\title{
Molecular Detection and Therapeutic Management of Feline Mycoplasmosis
}

\author{
P. Ameldev ${ }^{1}$, P.V. Tresamol ${ }^{1}$ \\ Department of Veterinary Epidemiology and Preventive Medicine, College of Veterinary and Animal Sciences, \\ Mannuthy, Kerala Veterinary and Animal Sciences University, India
}

\begin{abstract}
Mycoplasma haemofelis and Candidatus Mycoplasma haemominutum (formerly known as Haemobartonellafelis) are the causes of hemotropic mycoplasmosis in cats. The parasites attach to the surface of the red blood cell, and have the potential to cause severe alterations of the cell's shape, resulting in anaemia. A three-year-old tom cat was presented in University Veterinary Hospital with symptoms of lethargy, reduced appetite and fever for past 3 days. Clinical examination revealed increased temperature $\left(103^{\circ}-105^{\circ} \mathrm{F}\right)$, blanched mucous membranes and lymphadenopathy. Upon peripheral blood smear examination small coccoid organisms could be noticed in the periphery of the RBCs. Hematobiochemical examination revealed anaemia, thrombocytopaenia and decreased haematocrit values. The blood samples were subjected to DNA extraction and followed by Polymerase Chain Reaction which confirmed mycoplasmosis due to Mycoplasma haemofelis. The animal was treated with intravenous administration of oxytetracycline @ $10 \mathrm{mg} / \mathrm{kg} B W$ for five days along with prednisolone and vitamin supplements. Uneventful clinical recovery was noticed 7 days post therapy.
\end{abstract}

Keywords: feline mycoplasma, Mycoplasma haemofelis, molecular detection, therapeutic management

\section{Introduction}

Feline Mycoplasmosis/hemobartonellosis, also known as feline infectious anaemia (FIA), is a clinically important disease in the cats. It has been recognised since 1942. The disease may be acute or chronic. Although the organism produces some degree of anaemia in most cats, it also causes a wide range of other clinical signs, which vary from reduced appetite to severe pyrexia, vascular collapse and sometimes death. The disease is caused by Mycoplasmal bacteria that infects erythrocytes and characterised as cell wall-deficient, uncultivable bacteria that colonise the outside of erythrocytes and infect a wide range of vertebrate hosts. The organism is considered as pleomorphic and it can be noticed as rod-shaped, spherical, or ring-shaped and are found individually or in chains across the red cell surface. Haemotropic mycoplasmas were previously known as Haemobartonella and Eperythrozoon, but now are reclassified within the genus Mycoplasma according to 16S rRNA gene sequencing. The organism has got worldwide prevalence and arthropod vectors are considered to be the important mode of transmission. However the infection can also spread through the fight between cats, and during blood transfusion ${ }^{[1]}$. Molecular diagnosis and successful therapeutic management of a case of haemotropicmycoplasmosis is described in this article.

\section{Case History and Observations}

A three-year-old tom cat was presented with the symptoms of lethargy, reduced appetite and fever for past 3 days. Regular vaccination and deworming were followed and the animal was reared in a group along with other 3 cats of same age group. Upon physical examination animal was found to be dull and emaciated with a rough hair coat. Clinical examination revealed rectal temperature of $103.8^{\circ} \mathrm{F}$, blanched mucous membranes and lymphadenopathy (fig. 1 and 2). Microscopical examination of Giemsa stained Peripheral blood smears revealed small coccoid organinsms in the periphery of red blood cells suggestive of haemotropic mycoplasmas (Fig. 3). Hematobiochemical examination revealed anaemia along with thrombocytopaenia, granulocytosis and leucocytosis. Biochemical parameters like creatinine, Blood urea nitrogen,Alanine transaminase, total protein albumin, globulin and $\mathrm{A}: \mathrm{G}$ were found to be within normal range.

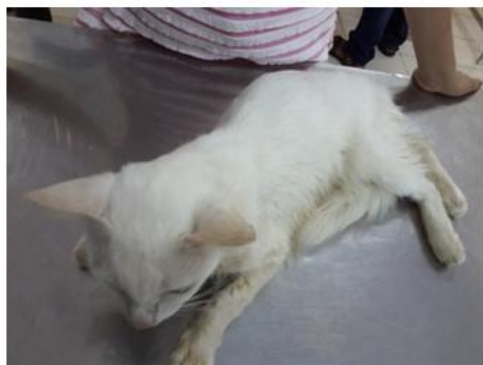

Fig. 1

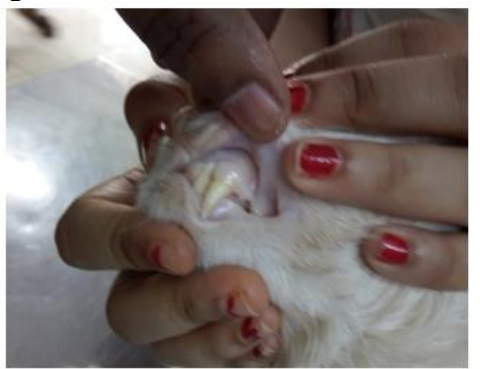

Fig. 2 


Table.1:Hematological parameters
\begin{tabular}{|ll|c|c|}
\hline Parameters & Unit & Result & Normal range \\
\hline WBC & $\left(10^{3} / \mu 1\right)$ & 24.4 & $5.5-19.5$ \\
\hline Lymphocytes & $\left(10^{3} / \mu \mathrm{l}\right)$ & 6.2 & $1.5-7.8$ \\
\hline Monocytes & $\left(10^{3} / \mu \mathrm{l}\right)$ & 0.9 & $2.5-12.5$ \\
\hline Granulocytes & $\left(10^{3} / \mu \mathrm{l}\right)$ & 17.3 & $2.5-12.5$ \\
\hline RBC & $\left(10^{6} / \mu \mathrm{l}\right)$ & 3.3 & $5.0-10.0$ \\
\hline HGB & $(\mathrm{g} / \mathrm{dl})$ & 5.9 & $8.0-15.0$ \\
\hline PCV & $(\%)$ & 20.6 & $30.00-40.00$ \\
\hline Platelets & $\left(10^{3} / \mu \mathrm{l}\right)$ & 98 & $300-800$ \\
\hline
\end{tabular}

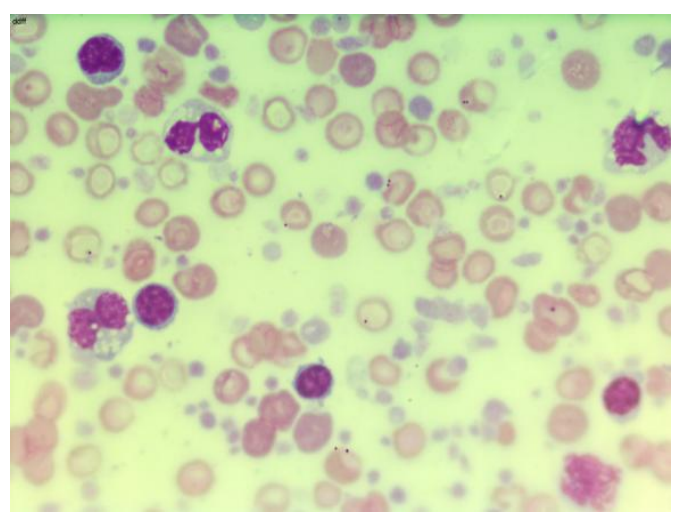

Fig. 3

Table.2:Serumbiochemicalparameters

\begin{tabular}{|l|c|c|}
\hline Parameters Unit & Result & Normal range \\
\hline Creatinine $(\mathrm{mg} / \mathrm{dl})$ & 1.591 & $0.8-2.4$ \\
\hline SGPT $(\mathrm{Iu} / \mathrm{l})$ & 81.72 & $12-130$ \\
\hline Total Protein $(\mathrm{g} / \mathrm{dl})$ & 7.92 & $5.7-8.2$ \\
\hline Albumin $(\mathrm{g} / \mathrm{dl})$ & 3.406 & $2.2-4.0$ \\
\hline Globulin $(\mathrm{g} / \mathrm{dl})$ & 4.556 & $2.8-5.51$ \\
\hline A/G ratio ratio & 0.74 & $0.35-1.5$ \\
\hline
\end{tabular}

\subsection{Molecular detection}

The DNA was extracted from the Anti-coagulant blood using the DNeasy® Blood and Tissue Kit, (QIAGEN)as per the manufacture's recommended protocol. Polymerase chain reactionamplification was carried out in $25 \mu$ l reaction mixture containing $12.5 \mu 1$ EmeraldAmp ${ }^{\circledR}$ GT PCR Master Mix, made Takara $7.5 \mu 1$ of nucleus free water, $1 \mu \mathrm{l}$ of each primers and $3 \mu \mathrm{l}$ of sample. The cycling was carried out in MJ mini personal thermal cycler (BIO RAD) by using the primers 5' GAAACTAAGGCCATAAATGACGC 3' as forward and 5'ACCTGTCACCTCGATAACCTCTA 3' as reverse respectively. The positive DNA of Mycoplasma haemofelis obtained from Dr SeverineTasker, School of Veterinary Sciences, Bristol University, U.K. was used as positive control for the above PCR reaction.

Table.2 PCR protocol

\begin{tabular}{|c|c|c|c|c|c|}
\hline No. & PCR & Te & \multicolumn{3}{|l|}{ Time } \\
\hline 1. & Initial denaturation & $98^{\circ} \mathrm{C}$ & \\
\hline 2. & Denaturation & $98^{\circ} \mathrm{C}$ & \multicolumn{2}{|l|}{$\frac{3 \mathrm{~min}}{10 \mathrm{sec}}$} & \\
\hline 3. & Annealing & $63^{\circ} \mathrm{C}$ & $30 \mathrm{sec}$ & 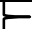 & 33 cycles \\
\hline 4. & Extension & $72^{\circ} \mathrm{C}$ & \multicolumn{3}{|l|}{$1 \mathrm{~min}$} \\
\hline 5. & Final extension & $72^{\circ} \mathrm{C}$ & \multicolumn{3}{|c|}{$10 \mathrm{~min}$} \\
\hline
\end{tabular}

The amplicons of Positive control and the test sample were visualized at 300bp. (fig.4). No, product was amplified in the negative control. 


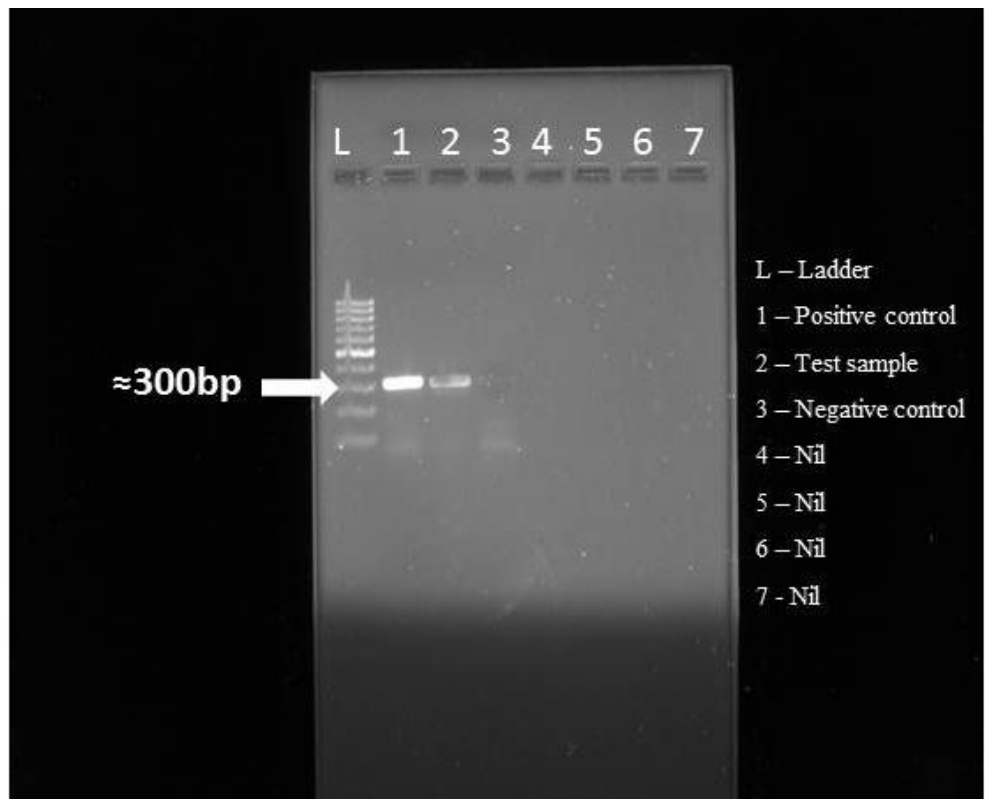

Fig. 4

\section{Treatment}

The animal was treated with intravenous administration of oxytetracycline injection @ 10mg/kg body weight for 7 days and intra muscular injection of prednisolone given at a tapering dose for five days along with fluids and multivitamin supplements. An uneventful clinical recovery was noticed after seven days of treatment.

\section{Discussion}

Feline mycoplasmas are found worldwide. Reports of disease from India are scanty. Diagnosis of the disease is based on the demonstration of the organism in stained blood smears and by molecular methods. Polymerase chain reaction is reported more sensitive than cytology ${ }^{[2]}$. The present study reports the molecular detection of Mycoplasma haemofelis using PCRfor the first time in India. Clinical signs of pallor, lethargy, anorexia and dehydration are described in feline haemotropicmycoplasmosis ${ }^{[3]}$, which are also found in the present case. Eventhough cytological diagnosis has poor sensitivity and specificity, diagnosis of the present case was done with cytology and further confirmed as Mycoplasma haemofelis by PCR. Severe anaemia with reduced haematocrit values was found in the case as already reported ${ }^{[2],[3],[4],[5]}$. The anaemia in haemotropic mycoplasmosis is attributed to destruction of erythrocytes. Clinical signs is mainly characterized by extra vascular haemolysis and the most common haematological abnormality is reported to be regenerative, macrocytic and normochromic anemia ${ }^{[2]}$. Tetracyclines or fluroquinolones are the drug of choices and oral administration of doxycycline $5-10 \mathrm{mg} / \mathrm{kg}$ PO q12-24h for 14 to 21 days is also recommended for treating infections with haemotropic mycoplasma ${ }^{[6]}$. Prednisolone is indicated to control self-destruction of RBC in case of mycoplasmosis. Present case was treated successfully with inj. Oxytetracycline at the dose rate of $10 \mathrm{mg} / \mathrm{kg}$ for five days along with Inj. Prednisolone $(0.5 \mathrm{mg} / \mathrm{kg}$ )tapering dose. Currently, little is known about the routes of transmission of hemoplasmas. Blood-sucking arthropods like fleas and ticks probably play an important role in the indirect transmission of the hemoplasmas ${ }^{[7], ~[2]}$. Furthermore, a direct transmission of hemoplasmas between cats has also been suggested. Therefore, special emphasis should be placed on the control of ectoparasites in the prevention and control of this disease

\section{Conclusion}

A case of haemotropicmycoplasmosis in a tom cat and its successful management is documented. The case was diagnosed based on cytology and PCR. The cat was successfully treated with parenteral administration of oxytetracycline and prednisolone. Based on the present study it is recommended that haemotropicmycoplasmosis should be included in the differential diagnosis of anaemia in cats.

\section{Acknowledgements}

The authors are extremely thankful to Dr. SeverineTasker lecturer in small animal medicine, the feline centre, School of Clinical Veterinary Science and Langford Veterinary Services, University of Bristol, Bristol, United Kingdom. For providing positive control of Mycoplasma haemofelis. Authors are grateful to The Dean, 
College of Veterinary and Animal Sciences, Mannuthy, Kerala Veterinary and Animal Sciences University for providing necessary facilities.

\section{References}

[1]. $\quad$ Tasker, S. L. M. R., and M. R. Lappin. "Haemobartonellafelis: recent developments in diagnosis and treatment." Journal of Feline Medicine and Surgery, 4(1), 2002: 3-11.

[2]. Willi, Barbara, Felicitas S. Boretti, SéverineTasker, Marina L. Meli, Nicole Wengi, Claudia E. Reusch, Hans Lutz, and Regina Hofmann-Lehmann. "From Haemobartonella to hemoplasma: molecular methods provide new insights." Veterinary microbiology, 125(3), 2007, 197-209.

[3]. Tasker, Séverine. "Haemotropic mycoplasmas: what's their real significance in cats?." Journal of feline medicine and surgery, 12, 2010, 369-381.

[4]. $\quad$ Sykes, Jane E. "Feline hemotropic mycoplasmas." Journal of Veterinary Emergency and Critical Care, 20, $2010,62-69$.

[5]. Tasker, S., S. H. Binns, M. J. Day, T. J. Gruffydd-Jones, D. A. Harbour, C. R. Helps, W. A. Jensen, C. S. Olver, and M. R. Lappin. "Use of a PCR assay to assess the prevalence and risk factors for Mycoplasma haemofelisand'Candidatus Mycoplasma haemominutum'in cats in the United Kingdom." The veterinary record 152 (7), 2003, 193-198.

[6]. Tasker, Séverine, Chris R. Helps, Michael J. Day, Dave A. Harbour, Timothy J. Gruffydd-Jones, and Michael R. Lappin. "Use of a Taqman PCR to determine the response of Mycoplasma haemofelis infection to antibiotic treatment." Journal of microbiological methods,56, 2004, 63-71.

[7]. Messick, Joanne B. "Hemotrophic mycoplasmas (hemoplasmas): a review and new insights into pathogenic potential." Veterinary Clinical Pathology, 33, 2004, 2-13. 